\title{
Analisis Sakarin dalam Jamu Kunyit Asam yang Dijual di Malioboro dan di Pasar Beringharjo Yogyakarta
}

Turmeric Herbal Saccharin Analysis in The Acid Sold in Malioboro and in Beringharjo Traditional Market Yogyakarta

Siti Fatimah ${ }^{1 *}$, Muji Rahayu ${ }^{2}$, Andra Lois T. Rinding ${ }^{3}$

${ }^{1,3}$ Prodi D3 Analis Kesehatan STIKes Guna Bangsa Yogyakarta

Jurusan Analis Kesehatan Poltekkes Kemenkes Yogyakarta

*Corresponding author: siti fatimah@gunabangsa.ac.id

\begin{abstract}
ABSTRAK
Jamu merupakan salah satu obat tradisional karena sebagian besar jamu dibuat dengan menggunakan bahanbahan alam atau tumbuhan-tumbuhan. Ada berbagai macam jenis jamu, salah satunya adalah jamu kunyit asam. Dalam komposisi jamu kunyit asam yang beredar mengandung zat tambahan seperti pemanis buatan, seperti diketahui harga jaтu kunyit asam di pasaran sangat murah dan terjangkau oleh kalangan masyarakat penikmat jamu. Hal ini menimbulkan kecurigaan, bahwa ada kemungkinan penambahan pemanis buatan pada jamu kunyit asam. Larangan obat tradisional mengandung bahan kimia sudah diatur dalam PERMENKES 007 tahun 2012 tentang registrasi obat tradisional, maka perlu dilakukan penelitian terhadap jamu kunyit asam yang dijual di Malioboro dan di pasar Beringharjo Yogyakarta. Penelitian ini bersifat deskriptif untuk mengetahui ada tidaknya sakarin dalam jamu kunyit asam yang dijual di Malioboro dan di pasar Beringharjo Yogyakarta. Metode yang digunakan dalam penelitian ini yaitu kromatografi lapis tipis (KLT). Apabila terdapat bercak noda dan nilai $R f$ sampel sama dengan nilai Rf baku pembanding maka dikatakan positif mengandung sakarin. Penelitian ini diperoleh nilai $R f$ sampel 0,5 sampai 0,71 dan terdapat 9 sampel yang memiliki nilai $R f$ dan fluoresensi yang sama dengan standar sakarin. Nilai $R f$ standar sakarin 0,63 dan fluoresensi berwarna ungu. Dari penelitian ini dapat disimpulkan terdapat $75 \%$ jamu kunyit asam yang dijual di Malioboro dan di pasar Beringharjo Yogyakarta mengandung sakarin.
\end{abstract}

Kata kunci: pemanis, sakarin, jamu kunyit asam, kromatografi lapis tipis.

\section{ABSTRACT}

Herbal medicine is one of traditional medicine since most herbal medicines made using natural materials or plants. There are various types of herbal medicine, one of which is herb turmeric acid. In composition herb turmeric acid circulating containing a substance additional as an artificial sweetener, as known price herbs turmeric acid in the market very cheap and affordable by the community audience herbs. This creates suspicion, that there is a possibility adding a sweetener made from herb turmeric acid. The prohibition of traditional medicines containing the Chemicals drugs is already set in PERMENKES 007 / 2012 on registration of traditional medicine, it is necessary to do research on herb turmeric acid sold in Malioboro and in Beringharjo traditional market Yogyakarta.This research is descriptive to know the whereabouts of saccharine in herbs turmeric acid sold in Malioboro and in Beringharjo traditional market Yogyakarta. Methods that used in research is thin Layers Chromatography (TLC). If there were patches stain and value $R f$ sample equal to value $R f$ raw comparison will positively containing saccharine. This research obtained the sample $R f 0,5$ until 0,71 and there is 9 sample of the $R f$ and fluorescence equal to standard saccharine. The standard $R f$ saccharine 0,63 and purple fluorescence. From this research we can conclude there are $75 \%$ herbs turmeric acid sold in Malioboro and in Beringharjo traditional market Yogyakarta containing saccharine.

Keywords: sweetener, saccharin, herbs turmeric acid, tamarind, thin layer chromatography.

\section{PENDAHULUAN}

Obat Tradisional adalah bahan atau ramuan bahan yang berupa bahan tumbuhan, bahan hewan, bahan mineral, sediaan sarian, atau campuran dari bahan tersebut yang secara turun temurun telah digunakan untuk pengobatan, dan dapat diterapkan sesuai dengan norma yang berlaku di masyarakat (PERMENKES No. 007, 2012). Berdasarkan Peraturan Menteri Kesehatan Nomor 007 tahun 2012 tentang registrasi obat tradisional, dalam peraturan ini dinyatakan bahwa obat tradisional dilarang mengandung etil 
alkohol lebih dari 1\%, kecuali dalam bentuk sediaan tingtur yang pemakaiannya dengan pengenceran, bahan kimia obat yang merupakan hasil isolasi atau sintetik berkhasiat obat, narkotika atau psikotropika, dan atau bahan lain yang berdasarkan pertimbangan kesehatan dan berdasarkan penelitian membahayakan kesehatan.

Jamu merupakan salah satu obat tradisional di masyarakat Indonesia. Jamu termasuk dalam obat tradisional karena sebagian besar jamu dibuat dengan menggunakan bahan-bahan alam atau tumbuh-tumbuhan. Secara farmakologi, jamu memiliki efek samping yang lebih rendah jika dibandingkan dengan obat-obatan kimia sintesis. Jamu dikenal sebagai minuman yang memiliki berbagai khasiat, seperti kebugaran/stamina, dan bahkan untuk mengobati penyakit (Handoyo, 2014). Salah satu aspek keamanan tersebut yaitu tidak adanya penyalahgunaan seperti penambahan bahan pemanis buatan berupa sakarin dalam pengolahan jamu.

Komposisi jamu kunyit asam yang beredar mengandung zat tambahan gula sebagai pemanis. Seperti diketahui harga jamu kunyit asam sangat murah dan terjangkau oleh kalangan masyarakat penikmat jamu. Mengingat harga pemanis alami lebih mahal dibandingkan harga pemanis buatan yang relatif lebih murah dan mudah dijumpai di pasaran maka tidak menutup kemungkinan adanya penambahan pemanis buatan dalam proses pembuatan jamu kunyit asam.

Sakarin memiliki tingkat kemanisan lebih tinggi, yaitu berkisar antara 30 sampai dengan ribuan kali lebih manis dibandingkan pemanis alami. Tingkat kemanisannya yang tinggi maka penggunaan pemanis buatan dalam produk pangan hanya dibutuhkan dalam jumlah kecil sehingga dapat dikatakan rendah kalori atau tidak mengandung kalori. Selain itu penggunaan pemanis buatan untuk memproduksi minuman atau makanan jauh lebih murah dibanding penggunaan pemanis alami (Saparinto dan Hidayati, 2006)

Peneliti mencurigai adanya sakarin yang ditambahkan ke dalam jamu kunyit asam karena berdasarkan survei yang dilakukan oleh peneliti dengan merasakan langsung rasa jamu kunyit asam yaitu terasa manis yang mengarah kepada kriteria pemanis sakarin. Sakarin apabila ditambahkan sebagai pemanis pada jamu kunyit asam akan meninggalkan rasa pahit dan tidak enak pada leher setelah mengkonsumsi minuman dengan penambahan sakarin. Penelitian yang yang sama pernah dilakukan oleh Yusuf dan Nisma (2013) di Wilayah Kelapa Dua Wetan Jakarta Timur ditemukan adanya pemanis buatan dalam jamu kunyit asam.

Mengingat dilarangnya sakarin pada jamu, maka diperlukan analisis sakarin pada jamu kunyit asam yang dijual di Malioboro dan di Pasar Beringharjo Yogyakarta. Kromatografi lapis tipis merupakan suatu teknik pemisahan yang menggunakan fase diam (stationary phase) dan fase gerak (mobile phase) (Gandjar dan Rohman, 2007). Prinsip pemeriksaan sakarin adalah sampel diekstraksi dengan asam sulfat dan etil asetat untuk mengikat dan menarik sakarin dari sampel, disaring dan dikeringkan. Residu dilarutkan kembali dengan asam sulfat dan ditentukan secara KLT.

\section{METODE PENELITIAN}

\section{Alat Dan Bahan}

Bahan yang digunakan pada penelitian ini yaitu Standar sakarin, sampel jamu kunyit asam dalam bentuk cair, $\mathrm{H}_{2} \mathrm{SO}_{4} 10 \%$, etil asetat $10 \%$, n-butanol, $\mathrm{NH}_{4} \mathrm{OH}$, etanol, aquades, bubuk Natrium sulfat $\left(\mathrm{Na}_{2} \mathrm{SO}_{4}\right)$, kapas, alkohol 70\%, 5\% brom dalam $\mathrm{CCl}_{4}$, dan $0,25 \%$ fluorescein dalam dimetil formamida 1:1. Peralatan yang digunakan pada penelitian ini yaitu satu set alat kromatografi lapis tipis, neraca, lampu UV, gelas beker, corong pemisah + rak, pipet volum $50 \mathrm{ml}$, pro pipet, pipet ukur $20 \mathrm{ml}$ dan $10 \mathrm{ml}, 1 \mathrm{ml}$, corong, erlenmeyer.

\section{Prosedur Penelitian}

\section{Pembuatan standar sakarin}

Bubuk sakarin ditimbang $10 \mathrm{~g}$ kemudian di- 
larutkan dalam $10 \mathrm{ml}$ alkohol : aquades (1:1). Proses ekstraksi

a. Sampel jamu kunyit asam dipipet sebanyak $50 \mathrm{ml}$ dan dimasukkan ke dalam erlenmeryer, diencerkan dengan $50 \mathrm{ml}$ aquades, dan dibiarkan sampai ampas jamu kunyit asam mengendap.

b. Sampel dipipet $50 \mathrm{ml}$ dan dimasukkan dalam corong pisah, diasamkan dengan $5 \mathrm{ml}$ asam sulfat dan $20 \mathrm{ml}$ etil asetat, kemudian sampel diekstraksi. Proses ekstraksi sampel diulang sebanyak 3 kali.

c. Hasil Ekstraksi disaring dengan menggunakan kapas dan bubuk $\mathrm{Na}_{2} \mathrm{SO}_{4}$ dan ditampung dalam wadah, kemudian diuapkan hingga kering.

d. Residu yang telah kering diencerkan dengan etil asetat $1 \mathrm{ml}$ dan siap untuk diteteskan pada plat KLT.

Analisis menggunakan kromatografi lapis tipis

a. Cuplikan diambil dengan tabung mikrokapiler sebanyak $20 \mu$, ditotolkan pada plat KLT dengan jarak $2 \mathrm{~cm}$ dari bagian bawah plat, dengan jarak antar noda $2 \mathrm{~cm}$ biarkan hingga kering

b. Eluen dibuat dengan campuran n-Butanol, Etanol, $\mathrm{NH}_{4} \mathrm{OH}$, aquades $(20: 2: 0,5: 4,5)$ dengan total volume $27 \mathrm{~mL}$. kemudian dimasukkan dalam chamber.

c. Chamber dijenuhkan menggunakan kertas saring, jika kertas saring sudah basah menanda- kan chamber sudah terjenuhkan oleh pelarut.

d. Plat KLT dimasukkan ke dalam chamber

e. Pelarut dibiarkan merambat dengan jarak rambat elusi $10 \mathrm{~cm}$ dari totolan.

f. Setelah mencapai jarak elusi, plat KLT dikeluarkan dan dikeringkan.

g. Hasil bercak warna yang timbul pada plat KLT dilihat dibawah sinar ultraviolet kemudian tandai bercak menggunakan pensil.

h. Nilai faktor retensi (Rf).

\section{HASIL DAN PEMBAHASAN}

Penelitian berjudul "Analisis sakarin dalam jamu kunyit asam yang dijual di Malioboro dan di pasar Beringharjo Yogyakarta pada tanggal 19-24 Mei 2016 di Balai Laboratorium Kesehatan Yogyakarta. Berdasarkan hasil penelitian yang telah dilakukan menggunakan metode kromatografi lapis tipis, didapatkan hasil dari 12 sampel jamu kunyit asam yang dijual di Malioboro dan di pasar Beringharjo Yogyakarta didapatkan 9 sampel mengandung sakarin. Analisis dengan kromatografi lapis tipis dapat ditentukan dengan nilai Rf, warna fluoresensi serta bentuk spot sampel sama dengan standar sakarin. Nilai Rf standar sakarin yaitu 0,63. Hasil Perhitungan Nilai Rf sampel jamu kunyit asam yang dijual di Malioboro dan di pasar Beringharjo Yogyakarta terdapat pada Tabel 1 .

Tabel 1. Hasil Rf jamu kunyit asam yang dijual di Malioboro dan di Pasar Beringharjo Yogyakarta dengan baku pembanding sakarin

\begin{tabular}{clcccc}
\hline No & Kode Sampel & $\begin{array}{c}\text { Jarak } \\
\text { Tempuh } \\
\text { Komponen }\end{array}$ & $\begin{array}{c}\text { Jarak } \\
\text { Tempuh } \\
\text { Pelarut }\end{array}$ & Nilai Rf. & $\begin{array}{c}\text { hasil } \\
\text { analisis }\end{array}$ \\
\hline 1 & Sampel 1 & $7,1 \mathrm{~cm}$ & $10 \mathrm{~cm}$ & $0,71 \mathrm{~cm}$ & negatif \\
2 & Sampel 2 & $6,3 \mathrm{~cm}$ & $10 \mathrm{~cm}$ & $0,63 \mathrm{~cm}$ & positif \\
3 & Sampel 3 & $6,3 \mathrm{~cm}$ & $10 \mathrm{~cm}$ & $0,63 \mathrm{~cm}$ & positif \\
4 & Sampel 4 & $6,3 \mathrm{~cm}$ & $10 \mathrm{~cm}$ & $0,63 \mathrm{~cm}$ & positif \\
5 & Sampel 5 & $6,3 \mathrm{~cm}$ & $10 \mathrm{~cm}$ & $0,63 \mathrm{~cm}$ & positif \\
6 & Sampel 6 & $6,3 \mathrm{~cm}$ & $10 \mathrm{~cm}$ & $0,63 \mathrm{~cm}$ & positif \\
7 & Sampel 7 & $6,3 \mathrm{~cm}$ & $10 \mathrm{~cm}$ & $0,63 \mathrm{~cm}$ & positif \\
8 & Sampel 8 & $6,3 \mathrm{~cm}$ & $10 \mathrm{~cm}$ & $0,63 \mathrm{~cm}$ & positif \\
9 & Sampel 9 & $6,3 \mathrm{~cm}$ & $10 \mathrm{~cm}$ & $0,63 \mathrm{~cm}$ & positif \\
10 & Sampel 10 & $6,3 \mathrm{~cm}$ & $10 \mathrm{~cm}$ & $0,63 \mathrm{~cm}$ & positif \\
11 & Sampel 11 & $5,0 \mathrm{~cm}$ & $10 \mathrm{~cm}$ & $0,50 \mathrm{~cm}$ & negatif \\
12 & Sampel 12 & $5,2 \mathrm{~cm}$ & $10 \mathrm{~cm}$ & $0,52 \mathrm{~cm}$ & negatif \\
13 & Standar sakarin & $6,3 \mathrm{~cm}$ & $10 \mathrm{~cm}$ & $0,63 \mathrm{~cm}$ & \\
\hline
\end{tabular}




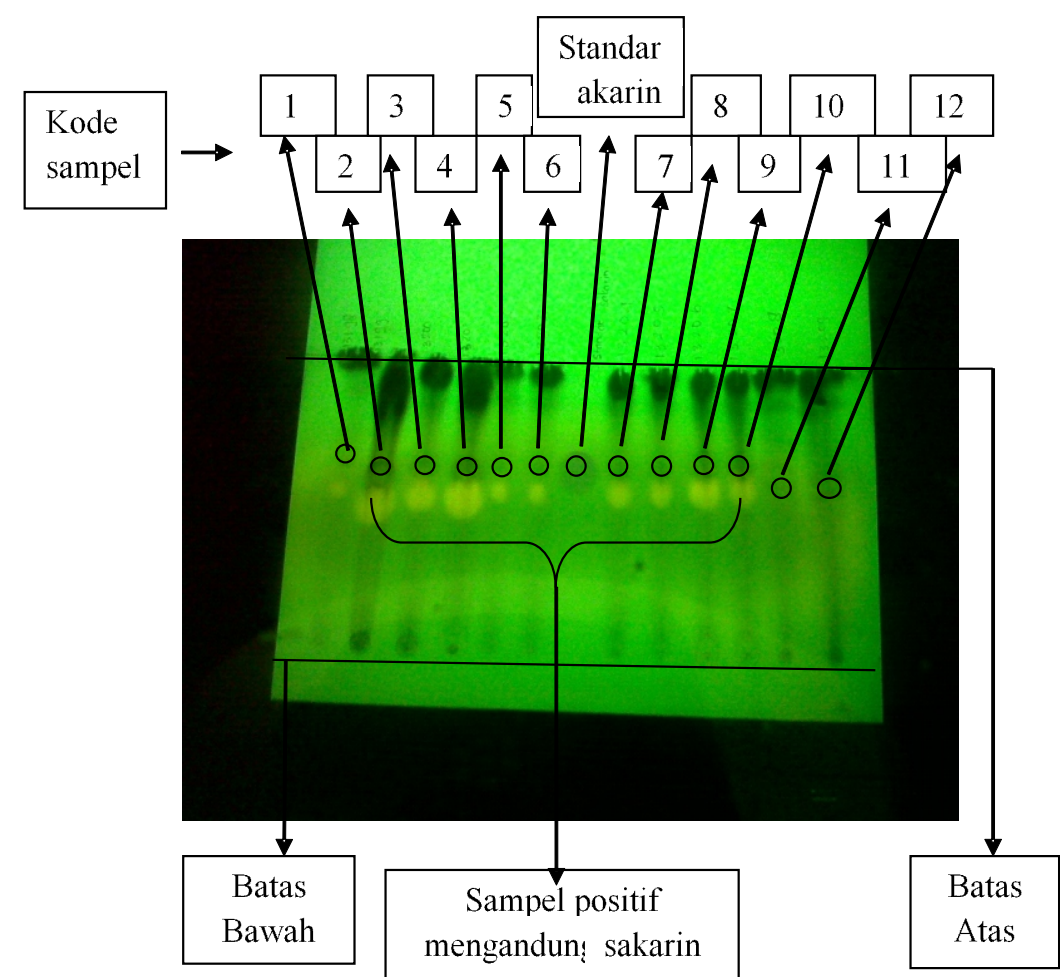

Gambar 1. Hasil flouresensi sampel jamu kunyit asam yang dijual di Malioboro dan di Pasar Beringharjo Yogyakarta

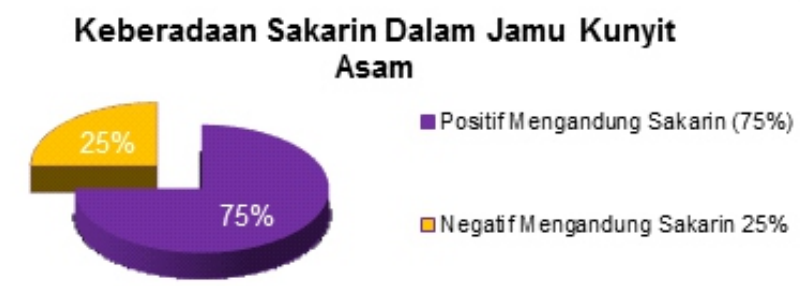

Gambar 2. Grafik presentase keberadaan sakarin dalam jamu kunyit asam yang dijual di Malioboro dan di Pasar Beringharjo Yogyakarta

Fluoresensi standar sakarin berwarna ungu dan bentuk spot bulat. Hasil flouresensi sampel jamu kunyit asam yang dijual di Malioboro dan di Pasar Beringharjo Yogyakarta pada Gambar 1.

Dalam bentuk presentase didapatkan $75 \%$ sampel jamu kunyit asam yang dijual di Malioboro dan di pasar Beringharjo Yogyakarta mengandung sakarin dan 25\% tidak mengandung sakarin. Grafik presentase keberadaan sakarin dalam jamu kunyit asam yang dijual di Malioboro dan di Pasar Beringharjo Yogyakarta terdapat pada Gambar 2.

Pada penelitian ini metode yang digunakan adalah metode kromatografi lapis tipis untuk membuktikan keberadaan sakarin pada sampel jamu kunyit asam secara kualitatif. Terlebih da- hulu dilakukan survei sampel pada pedagang jamu kunyit asam yang terdapat di Malioboro dan pasar Beringharjo Yogyakarta dan dilakukan pembelian sampel jamu kunyit asam yang cair kemudian dilakukan pelabelan pada setiap sampel. Sebanyak 12 sampel jamu kunyit asam yang dalam bentuk cair dianalisis di Balai Laboratorium Kesehatan Yogyakarta (BLK). Di BLK dilakukan lagi proses pengkodean terhadap sampel yang akan diteliti, dilakukan agar mempermudah dalam proses analisis. Kode diberikan sesuai dengan nomor urut sampel yang masuk di BLK .

Identifikasi sakarin dalam jamu kunyit asam metode KLT terlebih dahulu jamu kunyit asam dilakukan proses ekstraksi dimana sampel jamu kunyit asam dipipet sebanyak $50 \mathrm{ml}$ dan dima- 
sukkan ke dalam erlenmayer dan diberi kode sampel sesuai dengan kode sampel masuk di BLK. Setiap sampel diencerkan dengan aquades sebanyak $50 \mathrm{ml}$ dan ampas-ampas pada jamu sampel jamu kunyit asam dibiarkan mengendap. Tujuan jamu diencerkan adalah apabila sampel terlalu kental, proses ekstrasi tidak maksimal memisahkan sakarin dari sampel maka sampel perlu diencerkan. Kemudian sampel dipipet $50 \mathrm{ml}$ dan dimasukan ke dalam corong pisah.

Dalam corong pisah sampel ditambahkan dengan asam sulfat $10 \%$ dan etil asetat $10 \% \mathrm{ke}$ mudian diekstraksi dengan cara digojok di dalam corong pisah selama 3-5 menit. Tujuan penambahan asam sulfat untuk mengasamkan dan memisahkan atau mengikat sakarin dari sampel, sedangkan penambahan etil asetat bertujuan untuk mengikat sakarin dalam sampel. Proses ekstraksi diulang sebanyak 3 kali, hal ini dilakukan agar sakarin yang terdapat di dalam sampel benar-benar terpisah dari komponen sampel. Setelah proses ekstraksi terdapat 2 lapisan dimana sampel terdapat pada lapisan bawah sedangkan lapisan etil asetat berada di bagian atas. Hal ini disebabkan etil asetat memiliki berat jenis yang lebih ringan dibandingkan dengan sampel. Kemudian lapisan bagian bawah berupa sampel yang telah diekstraksi dibuang dan lapisan atas disaring dengan menggunakan bubuk natrium sulfat $\left(\mathrm{Na}_{2} \mathrm{SO}_{4}\right)$ anhidrat. Penyaringan dengan menggunakan bubuk natrium sulfat $\left(\mathrm{Na}_{2} \mathrm{SO}_{4}\right)$ anhidrat pada saat penyaringan berfungsi untuk menyerap kandungan air yang terkandung di dalam sampel. Hasil saringan ditampung dalam wadah kaca dan dibiarkan hingga kering dan mendapatkan residu. Tujuan dilakukan pengeringan dilakukan agar sisa- sisa air yang terkandung di dalam sampel menguap. Residu kemudian dilarutkan dengan asam sulfat $10 \%$ dan siap ditotolkan pada plat KLT, dilarutkan menggunakan asam sulfat $10 \%$ bertujuan agar asam sulfat tetap mengikat sakarin. Residu yang telah dilarutkan dengan asam sulfat $10 \%$, kemudian ditotolkan pada fase diam berupa silika gel dengan fase gerak yang terdiri dari campuran n-Butanol: etanol : $\mathrm{NH}_{4} \mathrm{OH}$ : aquades dengan perbandingan $(20: 2: 0,5: 4,5)$.

Pemilihan fase gerak didasarkan pada sifat fisika dan kimia yang dimiliki sakarin yaitu dapat larut dalam air dan menghasilkan fluoresensi bewarna ungu. Residu yang telah dilarutkan dengan asam sulfat $10 \%$, kemudian ditotolkan pada plat KLT secara perlahan untuk mendapatkan hasil yang baik dengan jarak $2 \mathrm{~cm}$ dari bagian bawah plat dan $2 \mathrm{~cm}$ antar noda. Fase gerak yang akan digunakan dijenuhkan terlebih dahulu dengan cara memasukkan kertas saring ke dalam campuran n-Butanol : etanol : $\mathrm{NH}_{4} \mathrm{OH}$ : aquades yang terdapat di dalam chamber, jika kertas saring sudah basah menandakan chamber sudah terjenuhkan oleh pelarut. Tujuan penjenuhan agar elusi dapat berjalan dengan cepat dan didapat hasil pemisahan yang baik. Plat KLT dimasukkan pada chamber yang sudah jenuh, kemudian ditunggu hingga eluen begerak mencapai garis batas. Plat KLT di keluarkan dari dalam chamber dan dibiarkan kering plat KLT disemprot dengan $5 \%$ brom dalam $\mathrm{CCl}_{4}$ kemudian dikeringkan, setelah kering disemprot lagi dengan $0,25 \%$ fluorescein dalam dimetil farmamid 1:1 kemudian dibiarkan kering. Penyemprotan dengan $5 \%$ brom dalam $\mathrm{CCl}_{4}$, dan $0,25 \%$ fluorescein dalam dimetil farmamid 1:1 bertujuan untuk mewarnai spot-spot yang ada pada plat KLT. Tujuan mewarnai plat KLT yaitu agar spot-spot yang dihasilkan oleh sakarin dapat terlihat jelas dan mempertegas warna ungu yang menandakan adanya sakarin bila dilihat fluoresensinya menggunakan sinar UV.

Hasil analisis dengan plat KLT yang telah diwarnai kemudian dilihat warna, bentuk di bawah sinar UV $254 \mathrm{~nm}$, kemudian dihitung nilai Rf-nya. Hasil yang didapatkan adalah terdapat 9 sampel yang memiliki bentuk spot, warna fluorosesnsi dan nilai $\mathrm{Rf}$ sama dengan standar sakarin yaitu bentuk spot bulat, fluorosesnsi berwarna ungu dan nilai Rf $0,63 \mathrm{~cm}$, yang dinyatakan positif mengandung sakarin sedangkan 3 
sampel negatif tidak mengandung sakarin karena bentuk spot, warna flourosensi dan nilai $\mathrm{Rf}$ tidak sama dengan standar sakarin.

Dari hasil penelitian terdapat $75 \%$ sampel positif mengandung sakarin dan menurut survei yang dilakukan oleh peneliti bahwa sebagian produsen jamu memang sengaja menambahkan sakarin dan pemanis buatan lainnya sebagai pemanis pengganti gula alami pada jamu kunyit asam, dan terdapat ketidakjujuran dalam berjualan jamu kunyit asam. Menurut PERMENKES Nomor 007 Tahun 2012 Tentang Registrasi obat Tradisional bahwa di dalam obat tradisional salah satunya adalah jamu tidak diperbolehkan mengandung etil alkohol lebih dari 1\%, kecuali dalam bentuk sediaan tingtur yang pemakaiannya dengan pengenceran, bahan kimia obat yang merupakan hasil isolasi atau sintetik berkhasiat obat, narkotika atau psikotropika, bahan lain yang berdasarkan pertimbangan kesehatan, serta harus di bawah pengawasan dinas kesehatan dan Badan POM.

Hasil penelitian jika dibandingkan dengan penelitian pada tahun 2013 yang dilakukan oleh Yusuf dan Nisma tentang analisis Pemanis Buatan (sakarin, siklamat dan aspartam) Secara Kromatografi Lapis Tipis Pada Jamu Gendong Kunyit Asam dan dari hasil penelitian tidak terdapat sakarin namun terdapat 5 sampel positif mengandung siklamat. Hasil penelitian ini juga dibandingkan dengan Batubara et al. (2012) dengan judul penelitian Analisa Pemanis Buatan (Sakarin, Siklamat Dan Aspartam) Secara Kromatografi Lapis Tipis Pada Jamu Kunyit Asam
Di Pasar Kramatjati, dari hasil penelitian tersebut tidak didapatkan hasil positif mengandung pemanis buatan pada Jamu Kunyit Asam Di Pasar Kramatjati.

\section{KESIMPULAN}

Berdasarkan hasil penelitian "Analisis Sakarin Pada Jamu Kunyit Asam Yang Dijual di Malioboro dan di Pasar Beringharjo Yogyakarta" dapat disimpulkan bahwa 75\% sampel jamu kunyit asam mengandung sakarin.

\section{SARAN}

Perlu dilakukan penelitian lebih lanjut untuk mengetahui kandungan bahan tambahan lain seperti siklamat, aspartam, dan bahan kimia lainnya pada sampel jamu kunyit asam.

\section{DAFTAR PUSTAKA}

Badan Pengawas Obat Dan Makanan Republik Indonesia No. HK. 00.05.4.2411. 2004. Ketentuan Pokok Pengelompokan Dan Penandaan Obat Bahan Alam Indonesia, Jakarta

Batubara IS, Yusuf Y, Indriani O. 2012. Analisa Pemanis Buatan (Sakarin, Siklamat Dan Aspartam) Secara Kromatografi Lapis Tipis Pada Jamu Kunyit Asam Di Pasar Kramatjati. Jurnal Lembaga Penelitan UHAMKA,Vol.14 No.1.

Gandjar IG, Rohman A. 2007. Kimia Farmasi Analisis. Pustaka Pelajar, Yogyakarta: 120, 353-355, 359-362.

Handoyo. 2014. Jamu Sakti Mengobati Berbagai Penyakit. Penerbit Dunia Sehat, Yogyakarta: 15-17, 21-23, 35, 44, 58.

Peraturan Menteri Kesehatan RI No, 007 Tahun 2012 Tentang Registrasi Obat Tradisional. Departemen Kesehatan RI, Jakarta.

Saparinto C, Hidayati D. 2006. Bahan Tambahan Pangan. Penerbit Kanisius, Yogyakarta: 78.

Yusuf Y, Nisma F. 2013. Analisis Pemanis Buatan (Sakarin, Siklamat, Dan Aspartam) Secara Kromatografi Lapis Tipis Pada Jamu Gendong Kunyit Asam Di Wilayah Kelapa Dua Wetan Jakarta Timur. Jurnal Lembaga Penelitan UHAMKA, Vol. 11 No. 2. 